\title{
CURSO DE GRADUAÇÃO NA ÁREA DE FORMAÇÃO DE PROFESSORES NA MODALIDADE DE EAD: A QUALIDADE SOB À ÓTICA SISTÊMICO- ORGANIZACIONAL ${ }^{1}$
}

\author{
(COURSE GRADUATE IN THE AREA OF TEACHER TRAINING IN THE FORM OF EAD: QUALITIY \\ FROM TUHE PERSPECTIVE SYSTEMIC ORGANIZATIONAL)
}

Ricardo Antunes de Sá

Universidade Federal do Paraná (Brasil)

\section{RESUMEN}

O artigo sistematiza os procedimentos, análises e resultados de uma pesquisa em nível de doutorado que tratou da questão da qualidade (formal e política) da licenciatura em Pedagogia - Séries Iniciais do Ensino Fundamental na modalidade de educação a distância no período de 1999 a 2002 da Universidade Federal do Paraná. Define qualidade. Revela as características e propriedades sistêmicas dos elementos constituintes do curso (professor especialista, orientadores acadêmicos, estudantes). Descreve a relação das partes e suas particularidades com o todo (curso) e deste em relação aos seus componentes (partes) com vistas a demonstrar, sob um olhar sistêmico-organizacional, a qualidade do curso. Propõe encaminhamentos teóricos e práticos para se garantir a qualidade nos cursos na modalidade de EaD.

Palavras-chave: educação a distância, formação de professores e educação a distância, graduação a distância.

\begin{abstract}
Article systematic procedures, analysis and results of a poll that addressed the issue of quality (formal and political) of the degree in Pedagogy - Initial Series of primary education in the mode of distance education in the period 1999 to 2002 of the Federal University of Parana. Defines quality (formal and policy). It shows the characteristics and properties of the systemic elements of the course (teacher specialist, guiding scholars, students). It describes the relationship of the parties and their particular with the whole (course) and this in relation to its components (parts) in order to demonstrate, on a looksystemic organizational, the quality of the course. Proposes referrals theoretical and practical to ensure the quality of courses in the form of distance education.
\end{abstract}

Keywords: distance education, professors formation and distance education, distance graduation. 
O texto procura retratar, sinteticamente, a pesquisa de cunho exploratório realizada na Tese de Doutorado que se inscreveu numa abordagem qualitativa por meio da qual procurou-se detalhar e analisar criticamente todo o processo de concepção, elaboração, implantação, desenvolvimento e avaliação do curso de graduação/licenciatura em Pedagogia - séries iniciais do Ensino Fundamental na modalidade de educação a distância da Universidade Federal do Paraná, no período de 1999 a 2002 (entre o fim do século XX e início do XXI), a qual buscou demonstrar a qualidade (formal e política) de curso de formação de professores na modalidade de educação a distância (EaD).

\section{O CURSO DE FORMAÇÃO DE PROFESSORES}

O curso de Pedagogia - Séries Iniciais do Ensino Fundamental na modalidade de EaD da Universidade Federal do Paraná (2000) tornou-se um dos primeiros projetos autorizados em 2000 pelo Ministério da Educação (quarto curso de graduação autorizado) na área de formação de professores na modalidade de educação a distância a funcionar no Brasil num momento histórico que, somente mediante parcerias interinstitucionais era possível realizar-se empreendimentos como o que foi implantado.

À época, ainda, os cursos de formação de professores na modalidade de educação a distância tinham como referência consolidada a experiência da Universidade Federal do Mato Grosso (Preti, 1996, 2000; Neder, 1999, 1996, 2000) que mantinha desde 1993 seu curso de Licenciatura para Formação de Professores de $1 .^{\mathrm{a}}$ à $4 .^{\mathrm{a}}$ Séries do Ensino Fundamental por meio de parcerias com a Secretaria Estadual de Educação do Mato Grosso e com as demais secretarias dos municípios parceiros pelo interior do estado.

Em 1999 a Universidade Federal do Paraná firmou convênio com a Universidade Nacional de Educação a Distancia - UNED da Espanha, com sede na cidade de Madrid, a qual por meio do curso Formación e Investigación em Educación a Distancia ofertado pelo Departamento de Didáctica, Organización Escolar y Didácticas Especiales da Facultad de Educación (Seminario-Taller de Postgrado) qualificou a equipe que assumiria o Núcleo de Educação a Distancia - NEAD.

A legislação que norteava as iniciativas educação a distância no Brasil nesse período (1999 - 2002) pautava-se pela Lei de Diretrizes e Bases da Educação - Lei n. ${ }^{\circ}$ 9.394/96 - (Brasil, 1996), por meio de seu Artigo 8o, pelo Decreto n. ${ }^{0}$ 2.494/98 
(Brasil, 1998a), pelo Parecer n. ${ }^{0}$ 301/98 (Brasil,1998b) e pelos Indicadores de Qualidade do Ministério da Educação (Brasil, 2000).

À época não havia recursos públicos federais destinados a projetos para a graduação a distância nas universidades públicas federais como ocorre desde 2006 com a chamada Universidade Aberta do Brasil (Brasil, 2006) que está fomentando, por meio de consórcio com as universidades públicas, a oferta de cursos de graduação na modalidade de educação a distância.

O financiamento da graduação se deu mediante as parcerias interinstitucionais estabelecidas, por meio da fundação da Universidade Federal do Paraná ${ }^{2}$ com entidades civis e órgãos públicos municipais do estado e fora do Paraná. Conforme os dados do relatório da Comissão Verificadora do Ministério da Educação (Brasil, 2004), considerando as turmas de 2000 e o número de 600 (seiscentos) ingressantes, 443 (quatrocentos e quarenta e três) concluíram o curso em 2004. A evasão no curso ocorreu, segundo o relato dos estudantes e orientadores acadêmicos, por motivos familiares, por dificuldades de adaptação à educação a distância, por motivos de saúde, por questões financeiras (o custo com o deslocamento para os encontros presenciais até os Centros Associados), por aposentadoria (estudantes) e pelo descumprimento dos convênios por parte das prefeituras e/ou instituições (parceiras) da sociedade civil da região onde residiam.

\section{ENCAMINHAMENTOS METODOLÓGICOS}

Para se chegar a comprovação de que houve qualidade (formal e política) foi preciso: a) Historiar o processo de concepção, de elaboração, de planejamento, de organização, de implantação e de avaliação da licenciatura em Pedagogia - Séries Iniciais do Ensino Fundamental na modalidade de educação a distância no período de 1999 a 2002 da Universidade Federal do Paraná; b) Sistematizar as representações do processo pedagógico-administrativo captadas nas entrevistas realizadas com os professores especialistas, com orientadores acadêmicos (professores tutores) e nos questionários aplicados junto aos estudantes; c) Evidenciar as características, as propriedades e as relações estabelecidas entre os elementos constituintes do sistema de educação a distância.

O processo de planejamento, organização e implantação do curso foi reconstruído de maneira cronológica (Selltiz et al. 1987, p.21) por meio das seguintes fontes: a) Artigos referentes ao curso; b) Ofícios da coordenação de 
curso; c) Comissão designada para a elaboração do projeto pedagógico do curso; d) Das 7 (sete) atas do Colegiado de Curso no período; e) Dos calendários de cada orientação acadêmica (tutoria) desenvolvida no período analisado; f) Dos calendários das orientações acadêmicas docentes a distância (telefone/chat), realizadas junto ao orientador acadêmico (professor tutor) no NEAD (Núcleo de Educação a Distância) no período de análise da pesquisa; g) Dos calendários de orientação acadêmica (tutoria) realizados (presencial e/ou a distância) junto aos estudantes nos Centros Associados; h) Dos Informativos dos Centros Associados; i) Dos cronogramas de todas as turmas por Centro Associado; j) Dos 115 (cento e quinze) calendários de cada disciplina ofertada no período; k) Das circulares emitidas pela coordenação de curso ao sistema de $\mathrm{EaD}$. As publicações de artigos e informativos realizadas no período; l) Da análise do material didático das disciplinas ofertadas no período da pesquisa por meio das entrevistas com professores especialistas, orientadores acadêmicos (professores tutores) e estudantes; m) Do questionário aplicado pela então Comissão Institucional de Avaliação de Curso (2002), com objetivo de caracterizar o perfil social, econômico e cultural dos estudantes; n) Do Relatório de Verificação, in loco, das condições institucionais (Brasil, 2004).

Entre 2003 e 2004, foram realizadas entrevistas semi-estruturadas com 11(onze) professores especialistas, com 20 orientadores acadêmicos (professores tutores) que atuaram no curso desde sua implantação. As categorias implícitas nas entrevistas abordavam: a) trabalho do orientador acadêmico; b) trabalho do professor especialista; c) material didático; d) processo de aprendizagem do estudante; e) processo de gestão pedagógica do curso; f) processo de comunicação entre os protagonistas do processo de educação a distância e; g) infra-estrutura do Centro Associado.

Foram aplicados 444 (quatrocentos e quarenta e quatro) questionários para todos os estudantes matriculados nas seis turmas. O percentual respondido ficou na faixa de $75 \%$ (setenta e cinco por cento), o que resultou em 336 (trezentos e trinta e seis) questionários respondidos. As categorias implícitas nos questionários foram as mesmas aplicadas aos professores especialistas e aos orientadores acadêmicos.

Os instrumentos de coleta de dados da pesquisa tiveram como referência para a sua elaboração, além da literatura sobre educação a distância, os Indicadores de Qualidade para Cursos de Graduação a Distância, da Secretaria de Educação do Ministério de Educação (Brasil, 2000 ${ }^{3}$ e 2003 ${ }^{4}$ ), o Relatório de Comissão Assessora para Educação Superior a Distância do MEC (Brasil, 2002a ${ }^{5}$ ) e o Roteiro para 
Avaliação de Cursos Superiores na modalidade a distância no ambiente da UniRede ${ }^{6}$ (Brasil, 2002b).

\section{TEORIA DA COMPLEXIDADE}

Tendo em vista os limites deste artigo a intenção aqui é fazer uma pequena referência aos elementos teórico-conceituais importantes do pensamento complexo que auxiliaram na fundamentação teórica da pesquisa. Vale lembrar, apenas, que o pensamento complexo apresenta os seguintes princípios: sistêmico ou organizacional, hologramático, retroatividade, recursividade, autonomia-dependência, dialógico e o da (re) introdução do sujeito cognoscente em todo o conhecimento.

Os conceitos de organização, sistema, dialogicidade, autonomia, pesquisa, interdisciplinaridade, interatividade, relação todo/parte/todo, interdependência (Moraes, 2005) serviram de referenciais de análise para construir e demonstrar a qualidade (formal e política) do curso.

O pensar complexo significa compreender cientificamente a interdependência e interconexão entre todos os fenômenos físicos, naturais e sociais. O pensamento complexo procura superar uma visão linear, reducionista e disjuntiva do conhecimento, do processo de (re)construção dos saberes científicos. O verdadeiro problema da reforma do pensamento, como diz Morin (2001a) é que se aprendeu a separar, mas é preciso (re)aprender a (re)ligar, estabelecer uma conexão completa que faça um círculo completo.

Complexidade é a trama dos acontecimentos, das ações, das interações, das retroações, das determinações, dos acasos, que constituem nosso mundo fenomênico (Morin, 2005). Entende a incerteza e as contradições como parte da vida e da condição do homem na terra e, ao mesmo tempo, sugere Morin a solidariedade e a ética como caminho para a (re)ligação dos seres e dos saberes (Petraglia, 2005).

Morin (2001 ${ }^{\mathrm{a}}$, p. 25) cita, recorrentemente, para fundamentar paradigmaticamente a construção do pensar de maneira complexa, a reflexão de Blaise Pascal (1623 - 1662) quando afirma que: "Sendo todas as coisas causadas e causadoras, ajudadas, mediatas e imediatas, e todas elas mantidas por um elo natural e insensível, que interliga as mais distantes e as mais diferentes, considero impossível conhecer as partes sem conhecer o todo, assim como conhecer o todo sem conhecer, particularmente, as partes [...]". 
Os fenômenos naturais, físicos, sociais, educacionais se manifestam nas ações integradas, de inter-retroações entre cada uma dessas dimensões e seu contexto. São as relações de reciprocidade, de tensionamento que possibilitam verificar como uma modificação do todo repercute sobre as demais dimensões envolvidas, bem como de que forma a modificação nessas dimensões repercutem no todo, no conjunto.

Um sistema apresenta qualidades, propriedades que não podem ser notadas no nível das partes isoladas. E nesse sentido, o todo será mais do que a soma das partes. Apresentará qualidades e propriedades distintas em relação às partes. Mas, por outro lado, dentro de um processo dinâmico e relacional, o todo pode inibir as qualidades e as propriedades das partes, o que fará com que o todo acabe ficando menor, qualitativamente falando, que a soma das partes que o compõem.

Para Carvalho, o sistema é uma unidade ambivalente, instável onde o todo e a parte por vezes se associam, por outras se dissociam, tendo em vista as imprevisibilidades, instabilidades e polidependências. Por outro lado, o sistema não pode ser uma totalidade fechada em relação ao seu entorno ou a outros sistemas porque isso faria com que estivesse condenado "[...] a ampliação da entropia, ao aumento da desordem sobre a ordem: à iminência do caos desorganizador, conforme prevê o segundo princípio da termodinâmica" (Carvalho, 2003, p.99).

Um sistema ${ }^{7}$ apresenta qualidades e propriedades próprias. Estas qualidades só aparecem quando o sistema se constitui num processo dinâmico de interação e interdependência entre as partes. Essas qualidades e propriedades que emergem do todo, do sistema, retroagem sobre as partes.

O sistema só se constitui quando existe organização e interação entre os elementos constituintes. A relação entre o todo, a totalidade sistêmica e as suas partes são mediadas por interações. É o conjunto dessas interações entre as partes in acto que gera uma organização que molda e configura sua estrutura interna. A organização dá coerência, regula, mantém, protege, rege o sistema, enquanto as interações exprimem o conjunto de relações, ações e retroações que se manifestam e se desenvolvem dentro de um sistema (Morin, 2001).

Nessa dinâmica relacional entre o sistema, organização e interação criam-se emergências, ou seja, qualidades ou propriedades que se manifestam ao nível do todo. As qualidades ou propriedades das partes dentro de um sistema não aparecem ou não existem quando essas partes são vistas isoladas do todo. Só podem ser percebidas ou desveladas pelo e no todo (Petraglia, 1995). 
Portanto, o curso foi compreendido como um sistema organizacional complexo, no qual seus elementos constituintes apresentam identidades próprias, funções específicas mas não se confundiam com o curso, quando esse é tomado numa perspectiva de conjunto, de complexidade. Complexidade entendida aqui como propriedade sistêmica que está presente em todos os "[...] domínios sistêmicoorganizacionais da vida, sejam eles de natureza física, biológica, antropológica, social política ou cultural" (Moraes, 2007). Esses elementos estabelecem relações, inter-relações, implicações mútuas as quais são simultaneamente solidárias, complementares e conflitantes, antagônicas (Almeida \& Carvalho, 2002).

\section{CONCEPÇÃO DE QUALIDADE (FORMAL E POLÍTICA)}

A qualidade do ponto de vista sistêmico-organizacional é entendida como uma emergência ${ }^{8}$ produzida no processo dinâmico de desenvolvimento do curso, onde as partes (elementos constituintes do sistema de $\mathrm{EaD}$ ) por meio de suas inter-relações e interdependências, levando em consideração suas identidades, foram produzindo um todo sistêmico (curso) com características/propriedades que conferiram ao curso uma qualidade (formal e política). Somente é possível perceber essa qualidade (formal e política) quando se olha a relação das partes (elementos constituintes) e suas particularidades com o todo (curso) e do todo em relação às partes. Se os componentes ou as partes (elementos constituintes) forem tomados isoladamente não é possível perceber a emergência (qualidade) do todo.

O Princípio Sistêmico ou Organizacional (Morin, 2000 ${ }^{\mathrm{a}}, 2000^{\mathrm{b}}, 2000^{\mathrm{c}}, 2001^{\mathrm{a}}$, $\left.2001^{\mathrm{b}}, 2002^{\mathrm{a}}, 2002^{\mathrm{b}}, 2002^{\mathrm{c}}, 2003^{\mathrm{a}}, 2003^{\mathrm{b}}, 2005\right)$ auxilia a conceber que o curso é um todo complexo que possui qualidades/propriedades que não se confundem com suas partes (elementos constituintes) as quais possuem suas identidades/características/ propriedades próprias que emergem dessa organização sistêmica. O todo é mais do que a soma das partes.

A dimensão formal da qualidade ${ }^{9}$ (Demo, 2002, 2004, 2006) pode ser interpretada num curso de graduação na modalidade de educação a distância como: a) Os recursos de infra-estrutura física na_sede e nos centros associados; b) Os recursos tecnológicos empregados para garantir a comunicação bidirecional e a interatividade entre os professores especialistas e os orientadores acadêmicos e esses com os estudantes; c) Os momentos presenciais e não-presenciais; d) A disponibilidade de material para leitura, consulta e pesquisa; e) Os espaços para os encontros presenciais e orientação acadêmica nos centros associados, etc. 
A dimensão política num curso de graduação, na modalidade de educação a distância, pode ser concebida:

- Pelo projeto pedagógico e suas características identitárias com a modalidade;

- Pelos seus objetivos pedagógicos, políticos e profissionais;

- Pela sua integração a políticas, diretrizes e padrões de qualidade definidos pelo Estado e pela instituição universidade;

- Pelo processo de avaliação, acompanhamento e promoção do estudante;

- Pela prática coletiva e democrática de gestão pedagógica e administrativa do curso;

- Pela cultura organizacional de cooperação, de compartilhamento e aprimoramento do processo didático-pedagógico entre os sujeitos, etc.

\section{CARACTERÍSTICAS E ELEMENTOS CONSTITUINTES DE UM SISTEMA DE EDUCAÇÃO A DISTÂNCIA}

As características emergentes de um sistema de EaD podem ser identificadas por meio das propriedades específicas desta modalidade educativa: a) Estudo individualizado e independente (autonomia/aprendizagem); b) Espaço e tempo distintos entre professor e estudante; c) Comunicação bidirecional (dialogicidade/ interatividade); d) Trabalho cooperativo (interdependência); e) Processo de ensinoaprendizagem mediatizado entre os sujeitos da ação pedagógica (material didático, meios tecnológicos, sistema de orientação acadêmica e de avaliação).

Os elementos constituintes de um sistema de EaD podem ser considerados como partes ou sub-sistemas que têm suas constituições e dinâmicas próprias, mas que não se confundem com o todo, embora se articulem entre si para produzirem o todo (aqui considerado o curso): a) Equipe multidisciplinar (professor especialista, orientador acadêmico e profissionais técnicos); b) Projeto Pedagógico (princípios norteadores, objetivos, matriz curricular, cronograma de curso, identidade da EaD); c) Material didático (impresso e/ou outras mídias); d) Centros associados (infra-estrutura administrativa e tecnológica de apoio); e) Estudantes (Aprendizagem/Identidade); f) Gestão/colegiado (Gestão pedagógico-administrativa, política institucional, convênios, custos). 


\section{PROFESSORES ESPECIALISTAS}

Os docentes que atuaram como professores especialistas tinham como responsabilidade:

- Ministrarem as disciplinas nos encontros presenciais;

- Supervisionarem os orientadores acadêmicos (professores tutores) por meio de telefone, $e$-mail e chat;

- Auxiliarem o orientador acadêmico (professor tutor) nas correções das avaliações (provas) realizadas pelos estudantes;

- Assessorarem o orientador acadêmico semanalmente por meio das "orientações acadêmicas do docente a distância” em datas e horários previamente acordados e calendarizados;

- Elaborarem o material didático de sua disciplina;

- Dividiram seus encargos didáticos na EaD com a educação presencial o que acarretou um aumento de trabalho.

Os professores especialistas que foram entrevistados evidenciaram profundo contentamento em relação ao desafio de fazerem um curso na modalidade de educação a distância e puderam desmistificar a imagem negativa que tinham da educação a distância. Tiveram que repensar suas práticas pedagógicas ao longo dos encontros presenciais realizados nos Centros Associados.

Segundo seus relatos, viveram momentos de profunda interação com outras culturas, outras práticas religiosas, com professores de regiões diversificadas do interior do país. Isso lhes trouxe muita experiência de vida, de reconhecer que as dificuldades do magistério são muito semelhantes nos rincões do Brasil, mas ao mesmo tempo perceberam a garra, o empenho, a luta de seus colegas de magistério (estudantes) para se qualificarem em uma modalidade que, para eles, também era nova e cheia de incertezas.

Amadureceram no trato com o novo ator deste processo pedagógico que no presencial não existe: o orientador acadêmico (professor tutor). Aprenderam a lidar com ritmos e processos de aprendizagem específicos da EaD. Entenderam que havia e há uma especificidade no trabalho do professor em processos mediatizados que é mais complexo do que o papel desenvolvido na educação presencial. 
Os professores especialistas foram construindo um modus operandi para trabalhar com os estudantes que não pertenciam ao ensino presencial. Teriam que levar em consideração que os momentos presenciais faziam parte de um sistema educativo que envolvia outras mediações (material didático, orientação acadêmica) que objetivavam garantir ao estudante condições de (re) construção do conhecimento e, portanto, que aprendesse. Os encontros se organizavam mesclando situações de exposição formal do conhecimento, com atividades individuais, de grupo e dinâmicas.

Os professores ressaltaram que participaram de um trabalho socialmente importante ${ }^{10}$, outros destacavam a aventura que foi esse empreendimento, por conta de ser uma "nova" prática docente, eivada de peculiaridades, de diferentes tempos e espaços.

O que acarretou esforço para o professor nessa modalidade foi a necessidade de planejar toda a sua ação didático-pedagógica que compreendia as ações nos encontros presenciais ${ }^{11}$, na elaboração do guia didático que não iria reproduzir os encontros presenciais, mas complementá-los com um roteiro para os períodos de estudos a distância e ações coordenadas e qualificadas estabelecidas na parceira com o orientador acadêmico (professor tutor).

\section{ORIENTADORES ACADÊMICOS (PROFESSORES TUTORES)}

Os orientadores acadêmicos (professores tutores) desenvolviam suas atividades de orientação acadêmica (tutoria) presenciais nos Centros Associados, às vezes em sua própria residência ou do próprio local de trabalho. Trabalhavam no magistério das primeiras séries do Ensino Fundamental em escolas municipais e/ou estaduais, exercendo funções docentes ou de coordenação pedagógica. Todos haviam se formados em curso de pós-graduação na área de $\mathrm{EaD}$ (Aperfeiçoamento em Tutoria e/ou Especialização para Professores).

Esses profissionais, ao longo dos encontros presenciais, em conformidade com a (s) disciplinas que iriam orientar (tutorar), participavam da "aula" do professor especialista. Após os encontros, o professor que vinha da sede (UFPR) reuniase com o orientador acadêmico (professor tutor) que iria acompanhar didáticopedagogicamente a disciplina, para discutirem os encaminhamentos teóricos e técnicos metodológicos durante o período de estudos a distância. 
As orientações acadêmicas eram desenvolvidas nos Centros Associados por meio de calendário semanal com informações de dias e horários para cada disciplina. Os recursos/meios de comunicação utilizados para a orientação não-presencial eram: telefone, $e$-mail e o correio.

Houve por parte dos orientadores acadêmicos (professores tutores) um compromisso pedagógico e profissional com os estudantes, em relação ao processo de aprendizagem. Se faziam sempre presentes nas reuniões de Colegiado de Curso por meio da representação que existia dos orientadores acadêmicos por Centro Associado, o que dava mais representatividade as decisões tomadas no âmbito do colegiado de curso.

Como todos os profissionais envolvidos neste curso de graduação a distância, disponibilizavam tempo para suas leituras e estudos no período da noite e nos finais de semana. No entanto todos foram unânimes em afirmar que atenderam seus estudantes inúmeras vezes em horários fora daqueles acordados para as tutorias a distância. Inclusive nas próprias residências eram recebidos telefonemas dos estudantes.

Em verdade, para os orientadores acadêmicos (professores tutores) era difícil deixar de atender os estudantes quando estes ligavam para suas casas, porque acabavam estabelecendo vínculos profissionais e pessoais. Muitos estudantes trabalhavam em escolas (públicas municipais e estaduais), nas quais esses orientadores acadêmicos (professores tutores) eram supervisores, diretores ou atuavam em sala de aula.

Esse vínculo ao que parece foi construído durante todo o curso pelos orientadores acadêmicos (professores tutores). Tornaram-se caminheiros numa estrada que poucos conheciam. As orientações acadêmicas (práticas tutorias) revelaram profundo envolvimento e conhecimento da vida e das dificuldades enfrentadas no processo de estudos a distância.

Foi uma atividade profissional que exigiu dos orientadores acadêmicos (professores tutores) uma ação firme e rigorosa quanto às orientações que davam aos estudantes, tendo em vista a grande responsabilidade que tinham com a aprendizagem dos estudantes.

O papel dos orientadores acadêmicos apresentou-se como fundamental no suporte aos estudantes, tanto do ponto de vista acadêmico, quanto do ponto de vista 
humano e pessoal. Ao longo do período de pesquisa, todos os orientadores acadêmicos entrevistados atuaram do começo ao fim da vigência das suas disciplinas. $\mathrm{O}$ vínculo que eles estabeleceram com os estudantes possibilitou que estes não desistissem do curso, aprendendo a organizar e a planejar seus estudos a distância, criando verdadeiras comunidades de estudos cooperativas e solidárias.

\section{GESTÃo PEDAGÓGICA E ADMINISTRATIVA}

A gestão pedagógica e administrativa do curso se revelou fundamental na pavimentação dos alicerces da graduação em EaD porque não se tinha até então, modelo institucional na universidade. Pelas próprias características do sistema de $\mathrm{EaD}$, a gestão foi se configurando numa ação pedagógica e colegiada, onde foi-se construindo uma identidade, na qual se articularam as divergências e as convergências, resultando ações dialógicas, cooperativas, solidárias com vistas à garantia dos parâmetros (indicadores) de qualidade do curso.

O projeto pedagógico do curso edificou-se à luz de princípios filosóficos e políticos concernentes à formação de professores (legislação), respeitando as características de um sistema de EaD, o qual apresentava: a) Cronograma de curso; b) Calendário para cada disciplina; c) Guia didático do curso - projeto pedagógico; d) Sistema de avaliação da aprendizagem e fluxo de correção das avaliações; e) Cronograma de orientação acadêmica para os estudantes (presencial e a distância); f) Cronograma de orientações acadêmicas docente a distância (do professor especialista) para o orientador acadêmico (professor tutor); g) Material didático impresso para cada disciplina e distribuído para todos os estudante; h) Procedimentos comunicativos permanentes (fluxo de informações ocorria por meio das circulares, editais, comunicados) com todos os envolvidos no curso por meio da Internet, telefone ou correio.

Estabeleceu-se carga horária destinada aos estágios supervisionados de prática de ensino, observando-se os dispositivos legais e organizando o seu desenvolvimento de forma a atender às características do estudo a distância. Definiu-se competências e atribuições: a) Aos professores especialistas; b) Aos orientadores acadêmicos; c) Aos diretores acadêmicos; d) À Coordenação de curso; e) Ao Colegiado de Curso; f) Aos estudantes, bem como preparou-os para os estudos mediatizados por meio de duas disciplinas introdutórias (EaD I e II). 
O professor especialista, o orientador acadêmico e o estudante não estavam constantemente no mesmo espaço e ao mesmo tempo, o que gerou práticas educativas mediatizadas, implicando:

- Num processo de organização sincrônica entre todos os elementos participantes do sistema e de cada participante em relação ao curso, bem como a observância constante das características e especificidades de uma modalidade educativa semi-presencial;

- Num comprometimento (profissional e ético) dos componentes do sistema de $\mathrm{EaD}$;

- Numa identidade construída pelos envolvidos no processo pedagógico mas ao mesmo tempo numa trama, numa teia que devia resultar em uma unidade de propósitos, intenções e ações a fim de se atingir a qualidade do curso, ou seja, uma unidade de propósitos e objetivos na diversidade de papéis e ações. "[...] Uno não se dissolverá no Múltiplo e o Múltiplo fará ainda assim parte do Uno" (Morin, 2005, p.77).

A gestão, embora dinamizada pela Coordenação/Colegiado de Curso contou com o envolvimento e trabalho de outros atores importantes dentro da trama complexa tecida pela educação a distância. Nas "pontas" (Centros Associados) estavam os diretores acadêmicos que tinham a função de ajudar a viabilizar a implantação de uma "nova" cultura educacional nos Centros Associados, criando as condições para que as práticas pedagógicas específicas dos estudos não-presenciais fossem incorporadas e vividas, além de garantirem o padrão de ensino acadêmico da universidade.

Eles prepararam e ajudaram os administradores dos Centros Associados e os orientadores acadêmicos (professores tutores) a instalarem uma ambiência acolhedora e comprometida com o curso, principalmente, na interação e na articulação com a cultura daquela comunidade, conforme atestaram as falas dos estudantes, dos professores especialistas e dos documentos pesquisados.

A participação da comunidade acadêmica do curso (professores especialista, orientadores acadêmicos, estudantes, diretores acadêmicos) nas reuniões de Colegiado traduziu-se numa prática democrática, solidária e cooperativa. O Colegiado foi o elo de unificação e de articulação das diversidades e das diferenças existentes. Foi a instância co-gestora que amalgamou, congregou e fortaleceu as práticas educativas dos orientadores acadêmicos (professores tutores), dos estudantes e dos professores especialistas. 
As reuniões dessa instância colegiada não tinha fins burocráticos, mas atender de um lado às demandas emergentes criadas pelo próprio desenvolvimento do curso nos Centros Associados e de outro lado no cumprimento das normas institucionais. Teve um papel político e pedagógico na mediada em que discutia e aperfeiçoava os procedimentos didático-pedagógicos voltados a atender à aprendizagem dos estudantes, ao mesmotempo que dialogava com os conflitos, com posições antagônicas do seus participantes, a fim de garantir o consenso para as suas deliberações.

Foi uma instância de interação, de diálogo e de aprendizado por parte de seus participantes. Como diz Assmann: "Interações se constituem pelo diálogo construtivo estabelecido entre diferentes aprendentes em um mesmo processo conversacional permitindo a co-criação" (Assmann, 2005, p.44).

Um dos expediente mais polêmicos deliberado pelo Colegiado de Curso foi a manutenção dos exames presenciais sem consulta nos Centros Associados. Embora pareça uma ação pouco pedagógica, tinha justamente a intenção de preservar a comunidade discente do curso de qualquer tipo de suspeita quanto à seriedade e o compromisso com a qualidade (formal e política) da graduação, como atestaram depoimentos. As avaliações se pautavam por uma preocupação com a produção intelectual do estudante. Eram formuladas questões dissertativas com vistas a avaliar o grau de compreensão do estudante, das leituras realizadas, da clareza na exposição das idéias, da diferenciação entre diversos olhares teóricos e de uma síntese provisória do conteúdo estudado. Para Leite (2006, p.142): “[...] a avaliação da aprendizagem do aluno não deve resultar em mera atribuição de notas, estando dissociada do projeto pedagógico e do processo de ensino-aprendizagem".

As práticas pedagógicas inovadoras denominadas Seminários Temáticos, mobilizaram orientadores acadêmicos (professores tutores) e professores especialistas e também, a comunidade das escolas onde os estudantes atuavam. Os Seminários Temáticos I, dentro de uma grade curricular com 29 (vinte e nove) disciplinas, tornaram-se um espaço de estudo e debate acadêmico interdisciplinar. Como pontuou-se acima essa experiência permitiu aos professores especialistas um salutar debate de idéias, possibilitando-lhes que as divergências e convergências epistemológicas (dialogicidade) aparecessem a partir de um tema gerador.

Do ponto de vista dos estudantes a EaD foi a oportunidade de compreender, de vivenciar, de analisar os temas do cotidiano escolar à luz das narrativas teóricas, possibilitando-lhes a compreensão da complexidade que cada fato, fenômeno ou evento humano dispensa, sobretudo quando se trata de educação. Os Seminários 
Temáticos I foram considerados por todos (orientadores acadêmicos, professores especialistas e estudantes) os que deles participaram como um avanço curricular em termos de uma nova prática docente na graduação, ou, poderia-se dizer que, do ponto de vista do pensamento complexo, os seminários representaram uma emergência. Se constituíram numa ação pedagógica na qual se (re) construiu conhecimento e se vivificou a prática docente dos professores especialistas do curso, contribuindo para a melhoria da qualidade do ensino e da aprendizagem.

\section{ESTUDANTES NA EDUCAÇÃO A DISTÂNCIA}

A grande maioria dos 600 (seiscentos) ingressantes no curso era mulher, em torno de setenta e cinco por cento, média feita das seis turmas, estavam na faixa de idade que ia de 31 a 50 anos, o que revelou um público adulto, com experiência de vida, que atuava nos dois turnos de trabalho da escola. Entre 10 e 20 anos era o tempo de serviço no magistério apresentado por 46\%(quarenta e seis por cento) dos estudantes. Eram trabalhadores(as) que respondiam por parcela importante da renda familiar, com encargos profissionais com filhos, marido e atividades domésticas.

Um dos processos didático-pedagógicos que contribuiu para que a qualidade do curso fosse alcançada foi a devida preparação dos estudantes para ingressarem num modus vivendi e operandi (EaD) diferente dos processos educativos presenciais. A criação das disciplinas de Concepção e Metodologia de Estudos em EaD I ${ }^{12}$ e II (Sa \& Barrenechea, 2000) prepararam esses estudantes para o árduo e sofrido processo de (re) construção do conhecimento Demo $(2006,2004,2002)$ dentro de um sistema de EaD. Tornaram-se as bases iniciais para que pudessem: a) Compreender as partes e o todo e a relação do todo com as partes do curso; b) Entender as características que cada "ator" tinha no sistema de educação a distância e suas relações entre si; c) Conhecer o projeto pedagógico do curso. Criaram novos hábitos de estudo, aprendendo a organizar sua vida acadêmica. Sem essa instrumentalização inicial e preparatória, as dificuldades dos estudantes poderiam ter sido maiores. Nos seus relatos e nos dos orientadores acadêmicos (professores tutores), ficou registrado a importância dessa preparação para a vida acadêmica na EaD.

A criação dos grupos de estudos se deu a partir do trabalho realizado na EaD II. O papel dos grupos de estudos tornou-se mais um elo de coesão, de união, de incentivo de interação de uns para com os outros. Estabeleceram-se links de companheirismo e de cooperação, os quais não permitiam a solidão e o desânimo. Relatos de 
estudantes confirmaram que aqueles que permaneciam sozinhos tinham maior dificuldade de acompanhar os estudos, sentiam-se solitários e desanimados. Um dos princípios apontados pelo Forgrad (2002) para o desenvolvimento de projetos de $\mathrm{EaD}$ é o trabalho colaborativo. A ação solidária e cooperativa entre os estudantes significou uma das características da $\mathrm{EaD}$ que se pretende de qualidade. Moraes (2005, p. 199) quando trata dessa questão escreve: “[...] a colaboração, a parceira e a solidariedade na maneira como nos relacionamos com os outros possibilitam as condições sistêmicas evolutivas dos seres vivos, caso contrário as relações vão se desintegrando aos poucos, dificultando diálogos interativos e o surgimento de espaço para que as interações humanas e sociais se desenvolvam, se ampliem e evoluam."

Os estudantes demonstraram por intermédio das entrevistas realizadas um profundo orgulho de serem acadêmicos da Universidade Federal do Paraná, de terem tido a oportunidade de estarem num curso de nível superior. Isso aliado ao empenho e à vontade demonstradas pode ser considerada, do ponto de vista simbólico, como um fator motivacional determinante para que também estudassem, lessem, empenhassem-se e realizassem os trabalhos/pesquisas e, com isso, permanecessem no curso.

A aprendizagem dos estudantes foi um processo que não esteve isolado dos demais fatores, atores e procedimentos pedagógicos, mas sim, foi produto de uma teia de inter-relações e interdependências (Moraes, 2004). Foi resultante de uma articulação (recursiva) das particularidades e das características de cada elemento do sistema de $\mathrm{EaD}$, voltadas para esse fim, na qual estiveram presentes:

- Os processos de organização e a ação da orientação acadêmica junto ao estudante;

- A dinâmica e implementação da orientação acadêmica (presencial e a distância) ao longo da vigência ${ }^{13}$ de cada disciplina;

- Os mecanismos de interação/comunicação desenvolvidos entre o estudante e o orientador acadêmico (professor tutor);

- O material didático impresso e de sua estruturação voltados para um indivíduo que não estava presente face-a-face, no qual se encontrava um texto introdutório para cada unidade didática, uma seleção de textos acadêmicos para estudos, uma indicação de leituras complementares e orientação para pesquisa; 
- A atuação do professor especialista nos momentos presenciais com estudantes e com os orientadores acadêmicos (professores tutores);

- A supervisão da ação do orientador acadêmico por meio dos recursos tecnológicos, semanalmente, durante a vigência da disciplina, por parte do professor especialista;

- As condições físicas, tecnológicas e materiais disponibilizadas nos Centros Associados;

- A ação pedagógica e administrativa de apoio dos diretores acadêmicos;

- $\quad$ E a gestão pedagógica e administrativa democrática e colegiada do curso.

Objetivamente constatou-se (orientadores acadêmicos e professores especialistas) que os estudantes com o passar do tempo, à medida que iam vivenciando os estudos semi-presenciais, mudavam de comportamento, passavam a perceber a necessidade de organizarem-se quanto às novas práticas de estudo. Passaram a apresentar uma nova postura frente à sua própria prática docente na escola onde atuavam. A aprendizagem envolve processos de auto-organização e de reorganização mental e emocional e se dá nas interações do indivíduo com o objeto de estudo e com os outros sujeitos numa relação intersubjetiva que viabiliza trocas intelectuais e diálogos necessários à (re)construção do conhecimento, à aprendizagem (Moraes, 2005).

Se num primeiro momento, eles não se manifestavam em aula presencial pois não sabiam colocar adequadamente suas idéias, bem como tinham dificuldades em escrever de forma mais clara e sistematizada no papel, à medida que iam lendo, estudando, realizando as pesquisas para os trabalhos e desenvolvendo projetos, sob à orientação e acompanhamento acadêmico (tutorial), percebeu-se (nos encontros presenciais e nas orientações acadêmicas), conforme relatos dos orientadores acadêmicos (tutores) que não eram mais os mesmos estudantes que haviam iniciado o curso. Seus escritos, suas falas passavam a ter mais fundamentação, mais coerência e mais consistência acadêmicas, o que lhes possibilitou mais fundamentação nas argumentações que faziam nos encontros presenciais e em suas escolas (comunidade).

Os estudantes participaram de concursos públicos, foram premiados por revista de reconhecimento nacional na área de educação, eram reconhecidos pelo seu aperfeiçoamento profissional por parte de suas escolas de origem. Num dos relatos prestado, por um dos orientadores acadêmicos, à Comissão de Verificação do MEC 
em 2004, ele se reportou a questão da qualificação dos estudantes (professores), dizendo: "Toda a sociedade e a comunidade foram beneficiadas. As mudanças eram percebidas por todos. Hoje isto faz a diferença. Os pais querem que os filhos estudem nas escolas onde trabalham as professoras que fazem o curso, pois agora elas estão mais qualificadas". (Brasil, 2004, p.20).

\section{MATERIAL DIDÁTICO UTILIZADO}

Os materiais didáticos impressos, de uma forma ou de outra, acompanhavam as estrutura definida pelo documento "Modelo para Elaboração do Material Didático" da Coordenação de Curso em (Prograd/Nead, 200o, p.8), na qual havia um texto introdutório, escrito pelo autor, e na seqüência, a seleção de autores ou textos mais acadêmicos que seriam lidos pelos estudantes.

Havia documento orientador que descrevia os passos detalhados para a confecção do material didático a ser elaborado pelo professor especialista. Sabe-se que o processo de construção de um texto que acolha uma linguagem científica e ao mesmo tempo seja dialógico é uma caminhada que não se faz numa primeira fornada.

O material didático do curso $^{14}$, além dos textos complementares que eram utilizados pelos estudantes e as indicações bibliográficas tinham que ser adquiridos pelos centros associados. Os professores produziram os fascículos (guias didáticos) para cada disciplina. Aqueles entrevistados que elaboraram os guias didáticos para as suas disciplinas avaliaram, de maneira geral, que os materiais atenderam aos objetivos e princípios do curso de formação de professores. A produção, a seleção e a organização de textos para processos formativos a distância devem sempre ser concebidos e pensados no interior de uma proposta curricular atrelados ao projeto pedagógico do curso (Neder, 2004).

Os materiais didáticos, sob o escopo de seus idealizadores mereceriam alterações, sobretudo em relação ao perfil do estudantes (professores); incorporando indicação de sites; reduzindo o número de textos para leitura e estudos; em alguns casos, reduzindo o número de trabalhos solicitados, deixando os materiais mais atrativos visualmente, melhorando a apresentação gráfica. 


\section{CONSIDERAÇÕES FINAIS}

Na formação de professores por meio da modalidade de educação a distância o êxito ou o fracasso, a qualidade ou a mediocridade dependerá de posturas teóricas e metodológicas que saibam contextualizá-la, compreendendo que a educação a distância não prescinde de um projeto pedagógico, de uma concepção de educação, de currículo, de avaliação, de ciência. Educação a distância exige também posturas sócio-cognitivas de compartilhamento, de trabalho colaborativo, de cooperação, de cumplicidade profissional, de diálogo, de respeito à diversidade, de acompanhamento do processo de aprendizagem dos estudantes, o que implica uma teia de sujeitos que se interdependem e se inter-relacionam numa caminhada pedagógica de (re)construção pessoal e coletiva dos saberes.

Numa perspectiva sistêmico-organizacional a qualidade é uma emergência originada da inter-relação, da interdependência, da articulação entre os elementos constituintes do curso e suas características e propriedades particulares. A qualidade não pode ser vista tomando-se um aspecto, um elemento, suas características ou propriedades, isoladamente. A qualidade do curso só pôde ser percebida quando se explora e analisa o todo, percorrendo dinamicamente seu processo de constituição, de construção e de implantação, bem como e, ao mesmo tempo, explorando e analisando as particularidades das partes, dos seus elementos constituintes e de suas possibilidades e limitações as quais constroem o todo e proporcionam-lhe a emergência da qualidade (formal e política).

A pesquisa procurou contribuir no sentido de apontar que, para que os cursos de formação de professores na modalidade de EaD apresentem qualidade (formal e política), é fundamental que sejam observadas as seguintes demarcações:

- As instituições que desejam implantar cursos de graduação na modalidade de $\mathrm{EaD}$ devem considerar a especificidade da modalidade, o que implica na criação de um espaço específico (núcleo, centro, instituto), com as condições físicas e tecnológicas para o desenvolvimento do ensino, da pesquisa e da extensão voltadas para a fundamentação teórica, técnica e epistemológica da EaD. Devem as instituições definirem uma política institucional efetiva para a modalidade.

- Os núcleos, centros ou institutos de $\mathrm{EaD}$ devem estar em permanente trabalho interdisciplinar com as áreas do conhecimento, por meio de projetos interinstitucionais, nos quais a natureza do conhecimento da área especifica 
se articula com as características e especificidades da EaD. Devem ter em seus quadros equipe multidisciplinar que possa desenvolver e implementar recursos multimidiáticos.

- A EaD tem muito o que contribuir para a chamada educação presencial, assim como esta tem para com a $\mathrm{EaD}$, porém ambas têm suas naturezas e suas especificidades que devem ser observadas quando se fala em qualidade (formal e política) da educação.

- A EaD deve ser concebida dentro do paradigma sistêmico o que implica conceber seus elementos constituintes, suas características, suas propriedades como uma rede, tendo em vista que há uma interdependência e uma interrelação permanente sem as quais não se consegue produzir a qualidade (formal e política).

- Especificamente nos processo de EaD na área de formação de professores é fundamental um percentual de encontros presenciais por área/disciplina nos quais o estudante estabeleça um vinculo maior com os professores.

- $\quad$ Os cursos de graduação não devem prescindir de conteúdos voltados para a ambientação do estudantes com os processos mediatizados de educação. $\mathrm{O}$ que implica em uma área/disciplina, em um seminário e/ou em encontros que didaticamente acolham o estudante na "nova" cultura de estudos nãopresenciais e mediados por recursos tecnológicos. Que possibilite ao estudante a informação e compreensão necessárias do projeto pedagógico do curso, dos mecanismos de avaliação e dos "novos" hábitos requeridos para estudar e aprender na modalidade de $\mathrm{EaD}$.

- Qualquer que seja o curso de graduação e, sobretudo, se for na área de formação de professores deve considerar fundamental a prática de trabalho colegiada. A prática colegiada é uma cultura que se constrói e que se torna condição sine qua non para que se edifique um sistema de EaD do ponto de vista político, pedagógico e epistemológico. A qualidade em sua dimensão política depende dessa cultura colegiada que envolve a coordenação e o colegiado de curso. Essa cultura se edifica do ponto de vista técnico por meio de um planejado e organizado sistema de comunicação entre todos os protagonistas do curso. Do ponto de vista político demanda um compromisso pedagógico e acadêmico com a modalidade de EaD. O que significa que os envolvidos acreditem no que estão fazendo e que acreditem nas potencialidades educativas da modalidade. A 
cultura colegiada só se efetiva quando existe também transparência nas ações e na informações, quando não há luta pelo poder, pelo controle, pela hegemonia de uns sobre outros. Portanto, a cultura colegiada vai além de uma retórica panfletária, implica numa ação/transformação coletiva e individual.

- Embora se saiba que a incerteza faz parte de qualquer empreendimento humano, qualquer iniciativa de formação em $\mathrm{EaD}$ deve considerar a necessária construção de um projeto pedagógico. Neste deverão estar previstos todos os procedimentos didáticos, pedagógicos e administrativos, sob pena de comprometer a qualidade. É fundamental que estejam previstos e que se disponha de recursos tecnológicos para os profissionais que venham a atuar, bem como para os estudantes nos Centros Associados (pólos).

- Processos de comunicação e interação entre estudantes, professores especialistas e orientadores acadêmicos são práticas imprescindíveis para a qualidade do curso. Nesse sentido é que se demarca a clareza que se deve ter em relação à EaD na qual tempo e espaço não estão permanentemente contíguos. Requer um processo pedagógico diferenciado em relação ao conhecido processo da educação presencial (face-a-face), na medida que seus agentes educativos estão em lugares e momentos síncronos ou assíncronos, os quais exigem mecanismos eficazes de comunicação permanente.

- Os Centros Associados como pontas físicas de um sistema de Ead devem ser locais de acolhimento do estudante, onde possam encontrar os recursos didáticos, pedagógicos, administrativos e tecnológicos para que tenham condições de estudar e aprender.

- Em relação aos orientadores acadêmicos, o entendimento que se depreende dessa pesquisa leva a considerar seu papel de extrema importância no processo de (re)construção do conhecimento que o estudante realiza. Esse profissional deve ter o mesmo status que o professor especialista tem no sistema de EaD. É preciso que quando do desenho de projetos de formação de professores, sobretudo, se observe a necessidade de considerar o orientador acadêmico como profissional da educação que está na "ponta" do sistema de EaD e tem a responsabilidade de garantir que a qualidade do processo de aprendizagem do estudante.

- O orientador acadêmico deve ter formação e qualificação na área que vai atuar. Não é possível que projetos/programas de EaD sejam de que área forem tenham 
nessa atividade profissionais leigos ou de outra área do conhecimento atuando na orientação acadêmica. A qualidade de seu trabalho também irá depender do número de estudantes que oriente. Entende-se que um número entre 30 (trinta) e 50 (cinqüenta) estudantes por área/disciplina é mais próximo da realidade e atenderia os padrões mínimo de qualidade. Ademais, entende-se, como se pôde verificar no curso objeto dessa pesquisa que o orientador acadêmico não deve acompanhar mais do que 3 (três) áreas/disciplinas concomitantemente.

- A EaD invoca um novo paradigma no qual o conhecimento é visto de maneira inter, multi e transdisciplinar. Sem negar a especificidade das áreas/disciplinas, a EaD propõe um modelo onde se possa olhar o fenômeno, o fato, o real pedagógico de maneira complexa. O que significa entender que o real educativo é tecido de multidimensionalidades e que as áreas do conhecimento podem e devem dialogar no sentido de compreender e produzir o conhecimento. Os Seminários Temáticos Irepresentaram essatentativa deavançarnuma concepção interdisciplinar, o que se revelou profundamente didática e qualitativamente adequada aos estudos de EaD e ao público dessa modalidade. Tornaram-se momentos de estudos coletivos e significativos para a compreensão complexa da realidade escolar.

- A participação do professor especialista na formulação do material didático (impresso) e nas sua atuações nos encontros presenciais nos quais estavam presentes os estudantes e os orientadores acadêmicos possibilitou um direcionamento didático-pedagógico dentro de cada área/disciplina. É preciso considerar algo decisivo na participação desse profissional num sistema de $\mathrm{EaD}$, qual seja seu engajamento epistemológico e político com a modalidade. Esse profissional precisa pela sua responsabilidade perante a comunidade acreditar, estar convencido das possibilidades formativas e emancipatórias da Ead. Estar convencido como profissional da educação de que participa de uma ação educativa que não pode prescindir da qualidade e que, seu papel, numa perspectiva sistêmico-organizacional, tem uma importância política e técnica.

- Os processos avaliativos devem ser orientados para a (re)construção do conhecimento, para a construção da autonomia intelectual, política e moral dos estudantes. A avaliação deve situar-se para além de qualquer perspectiva de memorização e sim, da construção de condições teóricas e práticas efetivas de um ação/reflexão/ação sobre a realidade, sobre a vida. A avaliação na EaD deve possibilitar o desenvolvimento de habilidades, de hábitos, de atitudes, de iniciativas que possibilitem o estudante enfrentar as incertezas do mundo. 
A EaD não deve ser uma panacéia para resolver todas as demandas de educação formal no Brasil e, quiçá, no mundo. A grande possibilidade que ela traz é incorporar o desenvolvimento científico e tecnológico em benefício da democratização e acesso ao conhecimento por parte da sociedade, sobretudo daqueles que não têm condições econômicas. A seriedade política e epistemológica de projetos/programas de $\mathrm{EaD}$ na área de formação de professores é que irá dar maior ou menor credibilidade a essa modalidade. É preciso entender que seus fins são os mesmos que a dita educação presencial, porém, apresenta características e propriedades específicas, as quais implicam numa concepção e abordagem sistêmico-organizacional, onde não é possível conhecer as partes sem conhecer o todo e não é possível conhecer as particularidades das partes sem conhecer o todo.

\section{NOTAS}

1 Este artigo é uma síntese de pesquisa desenvolvida na Tese de Doutorado de SÁ, R. A. Educação a Distância: estudo exploratório e analítico de um curso de graduação na área de formação de professores. Tese de Doutorado, Programa de Pós-Graduação em Educação, Linha: Educação, Ciência e Tecnologia, Faculdade de Educação, UNICAMP, 398 p. 2007. Tese de doutorado orientada pelo Professor Doutor Sérgio Ferreira do Amaral, coordenador do LANTEC (Laboratório de novas tecnologias aplicadas na educação) e docente do Programa de Pós-Graduação em Educação da Faculdade de Educação da UNICAMP, atuando na linha de pesquisa: Educação, Ciência e Tecnologia.

Fundação da Universidade Federal do Paraná para o Desenvolvimento da Ciência, da Tecnologia e da Cultura - FUNPAR.

(Brasil, 2000, p.3-11) "Indicadores de qualidade de cursos de graduação a distância: 1 - Integração com políticas, diretrizes e padrões de qualidade definidos para o ensino superior como um todo e para o curso específico; 2 - Desenho do projeto: identidade da educação a distância; 3 - Equipe profissional multidisciplinar; 4 - Comunicação/ interatividade entre professor e aluno; 5 - Qualidade dos recursos educacionais; 6 - Infra-estrutura de apoio; 7 - Avaliação de qualidade contínua e abrangente; 8 - Convênios e parcerias; 9 - Edital e informações sobre o curso de graduação a distância; 10 - Custos de implementação e manutenção da graduação a distância". (Brasil, 2003, p.1-15) "1 - Compromisso dos gestores; 2 - Desenho do projeto; 3 Equipe profissional multidisciplinar; 4 - Comunicação/interação entre os agentes; 5 - Recursos educacionais; 6 - Infra-estrutura de apoio; 7 - Avaliação contínua e abrangente; 8 - Convênios e parcerias; 9 - Transparência nas informações; 10 Sustentabilidade financeira".

5 (Brasil, 2002a, p. 11-37) “ 1- Introdução; 2- A integração da Educação Superior a Distância no Plano de Desenvolvimento Institucional; 3 - Elementos para compor um projeto de curso superior a distância: 3.1 - Processo de ensino e aprendizagem e organização curricular; 3.2 - Equipe multidisciplinar; 3.3 - Material didático; 3.4 - Interação de alunos e professores; 3.5 - Avaliação de ensino e de aprendizagem; 3.6 - Infra-estrutura de apoio; 3.7 - Gestão; 3.8 - Custos”. 
Em 2002, a Universidade Virtual Pública do Brasil - Pólo de Avaliação exarou Relatório Avaliativo de 4 cursos de graduação ofertados pelas seguintes universidades: Universidade do Estado de Santa Catarina, Universidade Federal do Mato Grosso, Universidade Federal do Paraná e Universidade Estadual do Ceará. Todas ofertavam cursos de graduação a distância na área de formação de professores. As dimensões avaliativas foram: pedagógica, material didático, orientação acadêmica, condições físicas e operacionais, modalidades de comunicação estabelecidas e o impacto social (Brasil, 2002b).

Sistema. [Do grego systema, reunião, grupo, pelo latim systema]. S.m. 1. Conjunto de elementos, materiais ou ideais, entre os quais se possa encontrar ou definir alguma relação. 2. Disposição das partes ou dos elementos de um todo, coordenados entre si, e que funcionam como estrutura organizada: sistema penitenciário; sistema de refrigeração. 3. Reunião de elementos naturais da mesma espécie, que constituem um conjunto intimamente relacionado: sistema fluvial; sistema cristalino. 4.0 conjunto das instituições políticas e/ou sociais, e dos métodos por elas adotados, encarados quer do ponto de vista teórico, quer do de sua aplicação prática: sistema parlamentar; sistema de ensino. 5. Reunião coordenada e lógica de princípios ou idéias relacionadas de modo que abranjam um campo do conhecimento: os sistema de Kant; o sistema de Ptolomeu. 19. [...] (Ferreira, 1986, p.1.594).

"Emergências: são propriedades ou qualidades oriundas da organização de elementos ou componentes diversos associados num todo, que não podem ser deduzidos a partir das qualidades ou propriedades dos componentes isolados, e irredutíveis aos seus elementos" (Morin, 2005, p.206-207). Conforme Giusta (2003, p.27) “[...] o que, em essência, determina o valor da EaD é a qualidade do projeto pedagógico a ser implementado: seus objetivos, a concepção de processo ensino/aprendizagem adotada, a pertinência e a atualidade dos conteúdos, as estratégias didáticas, as relações entre os participantes, a liberdade para buscar informações e colocar e discutir problemas reais e levantados pelo grupo [...] [e] a escolha dos suportes tecnológicos adequados aos propósitos visados [...]”. "Com um curso assim a UFPR cumpre um verdadeiro papel social"(Brasil. Formulário de Verificação in loco das condições institucionais. Curitiba, 2004, p.21).

Relato de professor especialista à comissão verificadora do MEC em 2004: "Precisei repensar toda a dinâmica de aulas para um período concentrado. Repensei toda a minha prática docente. Defendo criar um corpo docente e uma política institucional da UFPR para a EaD. Os módulos poderiam ser com menor número de disciplinas, para ter mais etapas presenciais" (Brasil. Formulário de Verificação in loco das condições institucionais. Curitiba, 2004, p.21)

Através da EaD I os estudantes conheceram como se daria a interação entre estudantes, professores especialistas e orientadores acadêmicos, o papel de cada um no sistema de $\mathrm{EaD}$; conheceram os procedimentos de avaliação previsto para a $\mathrm{EaD}$ e para o curso.

13 O termo vigência está sendo compreendido da seguinte forma: era o período que compreendia o primeiro encontro presencial até a última avaliação presencial do estudante. Em média, conforme exemplo constante no anexo, de 8 a 9 meses.

14 O espaço do artigo não permite um relato detalhado sobre a avaliação realizada pelos estudantes, professores especialistas e orientadores acadêmicos entrevistados. 


\section{REFERÊNCIAS BIBLIOGRÁFICAS}

Almeida, M. C.; Carvalho, E. A. (Org.) (2002). Morin, E. Educação e Complexidade: os sete saberes e outros ensaios. São Paulo: Cortez.

Assmann, H. (Org.) (2005). Redes digitais e metamorfose do aprender. Petrópolis: Vozes.

Carvalho, E. A. (2003). A complexidade necessária. Morin, E. in: Enigmas da cultura. São Paulo: Cortez.

Congresso Nacional (1996). Lei n. 9.394 de 20 de dezembro de 1996. Estabelece as Diretrizes e Bases da Educação Nacional, in: Diário Oficial da União de 23 de dezembro de 1996.

Conselho de Ensino, Pesquisa E Extensão (CEPE) (2000). Resolução n. 54/oo de 07 de abril de 2000. Estabelece o Currículo Pleno do Curso de Pedagogia - Séries Iniciais na modalidade de Educação a Distância do Setor de Educação Prograd/nead/setor de educação.

Demo, P. (2002). Complexidade $e$ aprendizagem: a dinâmica não-linear do conhecimento. São Paulo: Atlas.

Demo, P. (2002). Educação e qualidade. 9. ed. Campinas (SP): Papirus.

Demo, P. (2006). Formação permanente e tecnologias educacionais. Petrópolis (RJ): Vozes.

Ferreira, A . B. de H. (1986). Novo dicionário da língua portuguesa. 2. ed. Rio de Janeiro: Nova Fronteira.

Forgrad. Fórum nacional de Pró-Reitorias de Graduação das Universidades Brasileiras (2002).Educaçãoadistância:aspolíticas e as práticas, (27), mimeografado.

Giusta, A. S.; Franco, I. M. (Org.) (2003). Educação a distância: uma articulação entre a teoria e prática. Belo Horizonte (MG). PUC Minas: PUC Minas Virtual.

Leite, L. S. (2006). Teoria da distância transacional e o processo de avaliação da aprendizagem em EAD, in: Silva, M.; Santos, E. (Org.). Avaliação da aprendizagem em educação online. São Paulo: Edições Loyola, 141-152.

Ministério da Educação (1998a). Decreto n. 2. 494/98 (Regulamenta o Artigo 8o da Lei 9494/96 e dá outras providências). Diário Oficial, 10 de fevereiro de 1998.

Ministério da Educação (1998b). Portaria n. 301/98. Diário Oficial, o9 de abril de 1998.

Ministério da Educação (2003). Secretaria de Educação a Distância. Referenciais de Qualidade para Cursos a Distância. [en línea] Disponível em: http://portal.mec.gov.br/sesu/ ReferenciaisQualidadeEAD.pdf [consulta 2005, 14 de maio].

Ministério da Educação. Secretaria de Educação a Distância (2006). Universidade Aberta do Brasil. [en línea] Disponível em: http://www.mec.gov.br/ seed [consulta 2006, 7 de janeiro].

Ministério da Educação. Secretaria de Educação a Distância. Secretaria de Ensino Superior (2004). Formulário de Verificação in loco das condições institucionais. Curitiba (PR), pdf.

Ministério da Educação. Secretaria de Educação a Distância/Secretaria de Educação Superior (2002a). Comissão Assessora para Educação Superior a Distância. Portaria n. 335, de 6 de fevereiro de 2002. Relatório. [en línea] Disponível em: http://portal.mec.gov. br/sesu/index [consulta 2006, $14 \mathrm{de}$ janeiro].

Ministério da Educação. UNIREDE (2002b). Relatório do Comitê Consultivo do Pólo de Avaliação da UniRede - Curso de Graduação em Pedagogia, Licenciatura Plena com as habilitações magistério dos anos iniciais do Ensino Fundamental e magistério da Educação Infantil - UFPR. Salvador: UniRede/NAVE - Núcleo de Avaliação Educacional. ISP/UFBA, janeiro. 
Ministério da Educação/ Secretaria de Educação a Distância (2000). Indicadores de Qualidade para Cursos de Graduação a Distância. Rio de Janeiro: Tecnologia Educacional, v.29 (149), 3-11, abril/maio/junho.

Moraes, M. C. (2004). Pensamento ecosistêmico: educação, aprendizagem $e$ cidadania no século XXI. Petrópolis, R. J.: Vozes.

Moraes, M. C. (2005). Educação a distância e a ressignificação dos paradigmas educacionais: fundamentos teóricos e epistemológicos. Revista da FAEEB - Educação e contemporaneidade, Salvador, v.14, n⿳0. 23, 181-202, jan./jun.

Moraes, M. C. (2007). Ecologia dos saberes: complexidade, transdisciplinaridade $e$ educação. São Paulo: PUC/SP; Brasília: $\mathrm{UCB} / \mathrm{DF}$, mimeografado.

Morín, E. $\left(2001^{\mathrm{a}}\right)$. A cabeça bem-feita: repensar a reforma, reformar o pensamento. Tradução Eloá Jacobina, 5. ed. Rio de janeiro: Bertrand Brasil.

Morín, E. $\left(2001^{\mathrm{b}}\right)$. Ciência com consciência. Tradução Maria D. Alexandre \& Maria Alice Sampaio Dória. 5. ed. Rio de Janeiro: Bertrand Brasil.

Morín, E. $\left(2000^{\mathrm{a}}\right)$. Os sete saberes necessários à educação do futuro. Tradução de Catarina Eleonora F. da Silva e Jeanne Sawaya; revisão técnica de Edgard de Assis Carvalho, São Paulo: Cortez; Brasília, D.F.: UNESCO.

Morín, E. $\left(2000^{\mathrm{b}}\right)$. Meus Demônios. Tradução de Leneide Duarte e Clarisse Meireles. 2. ed. Rio de Janeiro: Bertrand Brasil.

Morín, E. $\left(2000^{c}\right)$. Saberes Globais e Saberes Locais - o olhar transdisciplinar. Rio de Janeiro: Garamond.

Morín, E. $\left(2002^{\mathrm{a}}\right)$. Embusca dosfundamentos perdidos - textos sobre o marxismo. Tradução Maria Lúcia Rodrigues e Salma Tannus, Porto Alegre: Sulina.

Morín, E. $\left(2002^{\mathrm{b}}\right)$. Ninguém sabe o dia que nascerá. Tradução Maria Leonor F. R. Loureiro, São Paulo: Editora UNESP;
Belém, P.A.: Editora da Universidade Estadual do Pará.

Morín, E. $\left(2002^{c}\right)$. A Religação dos Saberes - o desafio do século XXI. Tradução de Flávia Nascimento, 3. ed. Rio de Janeiro: Bertrand do Brasil.

Morin,E. $\left(2002^{\mathrm{d}}\right)$. Ométodo 5: a humanidade da humanidade - identidade humana. Tradução de Juremir Machado da Silva. Porto Alegre: Sulina.

Morín, E. $\left(2003^{\mathrm{a}}\right)$. Amor, poesia e sabedoria. Tradução Edgar de Assis Carvalho. 6. ed. Rio de Janeiro: Bertrand Brasil.

Morin, E. $\left(2003^{\mathrm{b}}\right)$. Para além da Globalização e do desenvolvimento: sociedade mundo ou império mundo? in: Carvalho, E. A.; Mendonça, T. Ensaios de complexidade 2. Porto Alegre: Sulina, 7-20.

Morin, E. (2005). Introdução ao pensamento complexo. Tradução Eliane Lisboa, Porto Alegre: Sulina.

Neder, M. L. C. (1996). Avaliação na Educação a Distância - significações para definição de percursos. In: Preti, O. (Org.). Educação a distância: inícios e indícios de um percurso. NEAD/IE - UFMT. Cuiabá: UFMT, 75-91.

Neder, M. L. C. (1999). Licenciatura em educação básica a distância - projeto expansão. Cuiabá, UFMT, mimeografado.

Neder, M. L. C. (2000). Licenciatura em Educação Básica a Distância: projeto expansão NEAD/UFMT, in: Preti, O. Educação a distância - construindo significados. Cuiabá:NEAD/IE - UFMT; Brasília: Plano, 183-227.

Neder, M. L. C. (2004). Metodologias para elaboração de materiais didáticos. Curitiba: Editora IPEX.

Preti, O.; al. (1996). Educação a distância: inícios e indícios de um percurso. NEAD/ IE - UFMT. Cuiabá: UFMT.

Preti, O.; al. (2000). Educação a Distância construindo significados. Cuiabá (MT): NEAD/IE - UFMT; Brasília: Plano. 
Prograd. Núcleo de Educação a Distância (NEAD).Setor deEducação. Coordenação do Curso de Pedagogia (2002). Modelo para Elaboração do Material Didático. Curitiba (PR).

Sa, R. A. (2007). Educação a Distância: estudo exploratório e analítico de um curso de graduação na área de formação de professores. Tese de Doutorado, Programa de Pós-Graduação em Educação, Linha: Educação, Ciência e Tecnologia, Faculdade de Educação, UNICAMP, 398.
Sa, R. A.; Barrenechea, C. A. (2000). Concepção e Metodologia de Estudos em Educação a Distância I e II. Curitiba, P.R.: PROGRAD/NEAD.

Selltiz; Wrightsman; Cook (1987). Métodos de pesquisa nas relações sociais - medidas na pesquisa social. 2. ed. tradutores Maria Martha Hubner d'Oliveira \& Mirian Marinotti Del Rey, volume 2, São Paulo: EPU.

\title{
PERFIL ACADÉMICO Y PROFESIONAL DEL AUTOR
}

Ricardo Antunes de Sá. Licenciado em Pedagogia - habilitação administração escolar pela Universidade Federal do Paraná (UFPR) em 1988. Habilitação em Supervisão Escolar pela Faculdade de Filosofia, Ciências e Letras Tuiuti em 1990. Mestre em Educação pela Universidade Federal do Paraná (UFPR) em 1997. Formación e Investigación em Educación a Distancia. Departamento de Didáctica, Organización Escolar y Didácticas Especiales. Facultad de Educación de la Universidad Nacional de Educación a Distancia (Madrid/Espanha). SeminarioTaller de Postgrado em 1999. Doutor em Educação no Programa de Pós-Graduação em Educação da Universidade Estadual de Campinas (UNICAMP) na área de Educação, Ciência e Tecnologia em 2007.

E-mail: antunesdesa@terra.com.br

DIRECCIÓN DO AUTOR

\author{
Universidade Federal Paraná \\ Setor de Educação \\ Departamento de Planejamento e \\ Administração Escolar \\ Rua General Carneiro, $460-4 .^{\circ}$ andar \\ 80.000-000 - Curitiba - Paraná \\ Brasil
}

Fecha de recepción del artículo: 19/01/08

Fecha de aceptación del artículo: 13/03/08 